Baruh, L., \& Cemalcılar, Z. (2018). When more is more? The impact of breadth and depth of information disclosure on attributional confidence about and interpersonal attraction to a social network site profile owner. Cyberpsychology: Journal of Psychosocial Research on Cyberspace, 12(1), article 1. https://doi.org/10.5817/CP2018$1-1$

\title{
When more is more? The impact of breadth and depth of information disclosure on attributional confidence about and interpersonal attraction to a social network site profile owner
}

\author{
Lemi Baruh¹ \& Zeynep Cemalcılar² \\ 1 Department of Media and Visual Arts, Koç University, Istanbul, Turkey \\ ${ }^{2}$ Department of Psychology, Koç University, Istanbul, Turkey \\ [Both authors contributed equally to this article.]
}

\begin{abstract}
Social network sites (SNSs) provide users with ample opportunity to share information about themselves and to engage in social browsing to learn about others. This article reports results from two experiments (with participants from the U.S.) that investigate the impacts of breadth and depth of information disclosed in a profile on viewers' attributional confidence about and interpersonal attraction to the profile owner. In the first experiment $(n=320)$, participants viewed a profile containing either low or high breadth of information. Analyses indicated that, higher breadth of information shared in the profile increased interpersonal attraction and that attributional confidence mediated this relationship. The second experiment $(n=537)$ tested the respective influences of breadth (low vs. high) and depth of disclosure (low vs. high) in a profile on perceivers' attributional confidence and interpersonal attraction. Analyses indicated that, while increasing the breadth of information had a positive impact on interpersonal attraction to profile owners, increasing the depth of information reduced attraction. Additionally, there was a significant interaction between breadth and depth of information in predicting attributional confidence; increasing the depth of information shared in an SNS profile enhanced attributional confidence only when the breadth of information shared was low.
\end{abstract}

Keywords: Social Network site profiles; impression formation; personal information; attributional confidence; selfdisclosure breadth; self-disclosure depth

\section{Introduction}

Following the rising popularity of social network sites (SNSs), a question that has received due attention in Computer Mediated Communication (CMC) research concerned the types of relationships that users engaged in (e.g., Baym, 2010; McKenna, Green, \& Gleason, 2002). Even though the majority of SNS activities are oriented towards supporting existing relationships (Lampe, Ellison, \& Steinfield, 2006), particularly among users with high sociability, SNS platforms are also used to expand personal networks and establish new connections (Bouchillon \& Gotlieb, 2016; Smith, 2011). Additionally, SNS platforms are increasingly used for not only socialization purposes but also as sources of information to evaluate individuals in a number of contexts, including education (e.g., Somers, 2017) and employment (e.g., Brown \& Vaughn, 2011; Scott, Sinclair, Short, \& Bruce, 2014). For example, a recent study by Hoek, O'Kane, \& McCracken (2016) indicates that employers access SNS profiles, both by asking permission as part of their official hiring procedure and observing covertly, to help determine a candidate's organizational fit. 
An important implication of such use of SNSs for evaluative purposes concerns the role information disclosure plays in impression formation (Nosko, Wood, \& Molema, 2010; Steijn \& Schouten, 2013). Whereas self-disclosure studies have increasingly focused on predictors of disclosure (e.g., Bazarova \& Choi, 2014; Choi \& Bazarova, 2015; Jin, 2013) and viewers' reactions to disclosure (e.g., Baruh \& Cemalcılar, 2015; Bazarova, 2012; Ledbetter et al., 2011), there is still a need to provide clearly articulated predictions about the impact of self-disclosure on first impressions about the owner of an SNS profile. Particularly, there is a dearth of research investigating the relative impacts of breadth and depth as two distinct dimensions of self-disclosure. Given these considerations, the present study reports findings from two experiments regarding the impacts of breadth and depth of self-disclosed information on viewers' attraction to the owner of the SNS profile.

\section{Self-Disclosure}

Self-disclosure and attraction in zero-acquaintance situations. Self-disclosure, defined as the sharing of any information about oneself to others (Collins \& Miller, 1994), has been identified as a key factor in relationship satisfaction and quality in both developing and established relationships (Altman \& Taylor, 1973). According to research on face-to-face relationships, in zero-acquaintance situations, higher levels of self-disclosure are associated with attraction. Specifically, according to a meta-analytical review by Collins \& Miller (1994), not only do we disclose more information to those we like but we also like people who disclose to us more.

The literature underlines two potential mechanisms through which increasing disclosure may contribute to interpersonal attraction. First, frameworks like the social penetration theory (SPT) (Altman \& Taylor, 1973; Taylor, 1979) view self-disclosure as social exchanges that can facilitate interpersonal connectedness. SPT posits that in initial stages of a relationships individuals typically make information about themselves available to each other in a symmetrical way, which, in turn, help enhance relational outcomes. Accordingly, over and above its informative utility, self-disclosure may increase interpersonal attraction by signaling positive intentions of the discloser (Collins \& Miller, 1994). In line with SPT, studies have shown that in zero-acquaintance situations, heightened selfdisclosure helps generate a sense of familiarity and closeness among dyads (e.g., Berger \& Calabrese, 1975; Sprecher, Treger, \& Wondra, 2013).

The second underlying mechanism for how self-disclosure may enhance interpersonal attraction in zeroacquaintance situations concerns the role self-disclosure plays in increasing the predictability of a relationship. According to uncertainty reduction theory (URT), uncertainty constitutes a negative state that individuals will be motivated to eliminate by finding cues that will help them better predict how a potential partner will behave in the future (Berger \& Calabrese, 1975). To that extent, self-disclosure early in a relationship may enhance interpersonal attraction by providing more cues that can reduce uncertainty (i.e., increase individuals' attributional confidence about the receiver).

On the other hand, some level of ambiguity may facilitate interpersonal attraction by adding a sense of mystery to a new relationship (Norton, Frost, \& Ariely, 2007). Specifically, studies have shown that reduction in uncertainty may have a negative effect on impression formation in the initial stages of relationships (e.g., Afifi \& Burgoon, 2000; Greene, Derlega, \& Mathews, 2006). Relatedly, information-processing models of attraction suggest that disclosure would result in positive relational outcomes only if the recipient evaluates the information positively (Ajzen, 1974). Additionally, lower levels of disclosure may also help reduce an unwelcome pressure to reciprocate to the person disclosing information, thereby enhancing relational outcomes (Archer \& Berg, 1978).

An important factor that may determine the extent to which self-disclosure enhances interpersonal attraction in early stages of relationships concerns the balance between different dimensions of information disclosed (Collins \& Miller, 1994; Nguyen, Bin, \& Campbell, 2012). One critical dimension of self-disclosure that has received due attention in relation to relationship initiation is what Greene et al. (2006) name as "informativeness". Accordingly, this dimension concerns "how much information the disclosure message provides about the discloser" and is generally defined in terms of "breadth" and "depth" of disclosure (p. 412).

Self-disclosure breadth. In the extant literature, the "breadth" aspect of disclosure has been defined in various ways. For example, according to Greene et al. (2006) "breadth" refers to variety of topics shared by the discloser. The term "breadth" has also been defined as "quantity" (e.g., Collins \& Miller, 1994) or "amount" (e.g., Altman \& 
Taylor, 1973; Lin \& Utz, 2017; Taddei \& Contena, 2013; Wheeless \& Grotz, 1976) of information, which have also been used interchangeably with frequency of disclosure (e.g., Limperos, Tamul, Woolley, Spinda, \& Sundar, 2014; Wheeless \& Grotz, 1976).

Despite such conceptual variation, however, the literature suggests that both of the potential mechanisms, summarized above, regarding the positive impact of disclosure to relational outcomes are applicable to disclosure breadth. First, as predicted by SPT, higher breadth of disclosure may breed liking via signaling to the receiver the discloser's desire to initiate a closer relationship (Taylor, 1979), communicating trust, and eliciting a positive affective response from the receiver (Gibbs, Ellison, \& Heino, 2006; Reis \& Patrick, 1996). Second, specific axioms of URT predict that in early phases of relationships, increases in amount of communication between strangers will reduce the level of uncertainty (Axiom 1), which will, in turn, produce interpersonal liking (Axiom 7) (Berger \& Calabrese, 1975; Sunnafrank, 1986).

Earlier research on CMC (e.g., Hancock \& Dunham, 2001) underlines the possibility that online contexts may differ from face-to-face relationships in terms of the role that these normative processes play in zero-acquaintance situations. However, perspectives like the social information processing (SIP) theory (Walther, 1992) suggest that just like in face-to-face relationships, CMC users are highly motivated to form impressions about others and reduce interpersonal uncertainty. Specifically, SIP predicts that particularly when non-verbal cues are missing, users will utilize a number of cues, such as content, delivery style and timing of self-disclosure to form impressions about others. In line with the premises of SIP, there is ample evidence suggesting that the mechanisms described above in relation to disclosure-liking effect will be present, and potentially be more intense, in CMC settings.

First, studies suggest that dyads tend to disclose more and with higher frequency in online contexts than in faceto-face contexts (Jiang, Bazarova, \& Hancock, 2011; Joinson, 2001; Schouten, Valkenburg, \& Peter, 2009; Tidwell \& Walther, 2002). This is particularly so among users who have favorable attitudes towards establishing relationships via SNSs (Attrill \& Jalil, 2011; Jin, 2013). Second, a number of studies report that irrespective of the actual content of messages shared, the frequency with which information is exchanged among dyads is positively associated with higher levels of sense of closeness and familiarity in CMC contexts (e.g., Kashian et al., 2017; Lin \& Utz, 2017; Pratt, Wiseman, Cody, \& Wendt, 1999; Tidwell \& Walther, 2002).

More specifically with respect to the relationship between breadth of disclosure and interpersonal attraction, evidence from research on CMC and relationship initiation suggests that increasing breadth of information shared in online relationships leads to higher liking and trust in different settings such as computer conferencing (Walther, 1993), newsgroup interactions (McKenna et al., 2002), and instant messaging (Jiang et al., 2011). Yet, the limited research on the impact of breadth of disclosure on SNS profile viewers' first impressions about the profile owner has provided mixed results (e.g., Antheunis, Valkenburg, \& Peter, 2010; Lampe et al., 2006; Limperos et al., 2014; Utz, 2010). Such mixed results are partly because these studies confound breadth of information with other factors associated with impression formation such as presence of photos (Limperos et al., 2014; Utz, 2010) or level of uncertainty reduction (Antheunis et al. 2010). On the other hand, research on online dating sites suggests that an increase in the amount of information (i.e., longer self-descriptions) enhances viewers' positive impressions (i.e., trust) about the profile owner (Toma \& Hancock, 2012). Relatedly, a recent study indicates that owners of SNS profiles that contain more information are more likely to be rated as likeable, extravert and friendly (Baruh, Cemalcılar, Bisson, \& Chisik 2017). Hence, our first two hypotheses propose:

H1. Higher breadth of information shared on a profile page will increase viewers' a) attributional confidence about and b) interpersonal attraction to profile owner.

H2. Attributional confidence will mediate the relationship between breadth of information shared and viewers' interpersonal attraction to the profile owner.

Self-disclosure depth. While disclosure of information may both signal discloser's willingness to further develop the relationship and help decrease uncertainty, the extent to which disclosure would increase interpersonal attraction is contingent upon timing and the context of the disclosure (Derlega, Winstead, \& Greene, 2008; Ignatius \& Kokkonen, 2007). For example, SPT suggests that the depth of disclosure in a relationship should gradually increase as the relationship develops (Altman \& Taylor, 1973). Greene et al. (2006) define depth as the level of 
intimacy of disclosed information. Accordingly, while conducive to reducing uncertainty, disclosing intimate information (i.e., information with higher depth) too early in a relationship (such as a zero-acquaintance situation) may result in lower interpersonal attraction. Research underlines two key reasons for this outcome. First, disclosure of intimate information may be perceived as inappropriate and as a violation of norms regarding tactfulness, especially during the initial stages of a relationship. Second, and relatedly, it has been suggested that intimate disclosures may cause reactance by creating an undue pressure to reciprocate the disclosure) (Archer \& Berg, 1978; Collins \& Miller, 1994).

Within the context of SNS-based interactions, studies indicate that users' decisions regarding disclosure of information reflects social expectations about the need to gradually increase depth of information shared (Marwick \& boyd, 2011). This is largely due to the openness of the participation structure-defined in terms of the size of the group and directedness of communication-of SNSs (Herring, 2003). This open participation structure of many SNSs allows for information to be visible to a wide circle of (both intended and potentially unintended) recipients that may include friends, acquaintances, and strangers (Bazarova, Taft, Choi, \& Cosley, 2013). Thus, SNS users have been observed to be more likely to increase the depth of disclosure only after they establish a sense of closeness; and, when they start disclosing information with more depth, they tend to prefer more directed forms of communication like a private message over, for example, a status post (Merkle \& Richardson, 2000).

Research on the impact of disclosure depth on interpersonal attraction on SNSs parallels findings from studies on face-to-face interactions. Specifically, in face-to-face contexts, it has been observed that while a boon to relational certainty, disclosure of intimate information may be deemed inappropriate in zero-acquaintance situations (Chaikin \& Derlega, 1974). In a similar vein, a study by Bazarova (2012) suggests that in SNS sites, viewers consider disclosure of intimate information as appropriate only when it is shared privately (rather than with all the network). In line with these normative expectations regarding disclosure of intimate information in SNSs, a recent study indicates that within the context of Twitter, a platform within which profiles are typically open to public, increasing the depth of information shared in Tweets increased profile viewers' attributional confidence about the profile owner but also decreased interpersonal attraction (Baruh \& Cemalcılar, 2015). Likewise, a longitudinal study of relationship formation and development on SNSs indicates that intimate information shared on SNSs is rated as less appropriate by profile viewers; and consequently, users sharing more intimate information are perceived to be less attractive (Orben \& Dunbar, 2017). Hence, we predict that:

H3. Higher depth of information shared on a profile page will increase viewers' attributional confidence about profile owner, which will, in turn, increase interpersonal attraction.

H4. After accounting for the effects of attributional confidence on interpersonal attraction, higher depth of information shared will decrease viewers' interpersonal attraction to the profile owner.

Respective impacts of breadth and depth of disclosure. To our knowledge, there is a dearth of studies that investigate the relative influence of these two dimensions (breadth and depth) of disclosure on interpersonal attraction and how they interact with each other within the context of SNSs. The Realistic Accuracy Model (Funder, 1995; Funder, 2012) provides a framework within which we can consider the respective roles that breadth and depth of disclosed information may play in evaluation of an SNS profile. According to this model, accuracy of the judgment about a person depends on: availability of a "good target" who is transparent with their thoughts and behavior, availability of "good information" with sufficient breadth and quality (i.e., relevance of information for making evaluations), and judges' willingness and ability to first detect and then utilize the information. While the applications of this model specifically focus on objective measures of accuracy such as inter-judge reliability (Beer \& Brooks, 2011; Beer \& Watson, 2010), its premise has implications for the role breadth and depth of information may play in profile evaluation in SNSs. This is particularly so for attributional confidence-which entails viewers' evaluation about the accuracy of their own judgments. As discussed in detail below, our last question in this study concerns this interaction between breadth and depth of information.

On the one hand, whereas increasing the quantity of information provides more data points for making judgments, concurrently increasing intimacy of information may further enhance attributional confidence by revealing relevant information about source characteristics. On the other hand, sheer increase in amount of information does not necessarily lead to better judgments about others. According to RAM, certain types of 
information (e.g., those that provide insights about feelings and values rather than hobbies or activities) are more likely to enhance individuals' ability to make judgments about others (Funder, 1995). Considered from this perspective, it is possible that concurrently increasing breadth and depth of may result in crowding-out of intimate information with higher potential diagnostic value. In various fields, such as economics, public policy and consumer behavior, the term crowd-out is used to refer to how directing a decision maker's attention to one (or more) piece(s) of information may compromise the decision maker's ability to utilize the relevant information (e.g., Anderson \& de Palma, 2009, 2012; Perry \& Blumenthal, 2012).

Such crowding of relevant information is connected to what has been named as information overload, which can be defined as the point where decision makers cannot extract the necessary knowledge from available information because of the availability of too much information, combined with limited processing capacity and/or time (Eppler \& Mengis, 2004; Jackson \& Farzaneh, 2012; Nelson, 1994). Research on information overload suggests that there will often be an inverse relationship between information quality-defined as the extent to which information fulfils the needs of the users - and amount of information being provided to users (Katzer \& Fletcher, 1992; Stvilia, Twidale, Smith, \& Gasser, 2005). In literature on consumer-decision making, for example, studies have repeatedly found evidence indicating that increased amounts of information leads to lower decision quality (e.g., Chen, Shang, \& Kao, 2009; Perry \& Blumenthal, 2012).

There is growing evidence suggesting that information overload may have important consequences for utilization of SNSs. For example, earlier research indicate that information overload may result in users feeling overwhelmed, stressed and dissatisfied with an SNS platform, and may even lead to withdrawal from a platform (e.g., boyd, Perez, \& Loyola, 2008; Eppler \& Mengis, 2004; Koroleva, Krasnova, \& Günther, 2010). While we were unable to locate direct evidence regarding how information overload may influence person perception in SNSs, it has been observed that information overload in SNSs divert users' attention from complex information (e.g., Jones, Moldovan, Raban, \& Butler, 2008; Jones, Ravid, \& Rafaeli, 2004). Given studies indicating that SNS users spend very limited time in perusing SNS profiles of others (e.g., Baruh \& Cemalcılar, 2015; Tobii Technology AB, 2012), it is possible that increasing the breadth of information will lead to a similar information overload that will reduce the ability of users to utilize the information with higher diagnostic potential (i.e., information with higher depth) to reduce uncertainty about the profile owner. Given these considerations, we further investigate the following research question:

RQ1. How do breadth and depth of information shared in a profile interact in predicting attributional confidence about the profile owner?

To investigate the hypotheses and research question described above, we present results from two online experiments. Because there is inconclusive evidence on the impact of breadth of information on perceivers' judgments in the SNS context, we first aimed to establish this association. Hence, the first study focuses solely on breadth of information ( $\mathrm{H1}, \mathrm{H} 2)$. Next, the second study considers the respective and joint effects of breadth and depth of information on profile viewers' attributional confidence about and interpersonal attraction to the profile owner (H1, H2, H3, H4, RQ1).

\section{Study 1}

\section{Method}

Participants and procedure. The sample comprised 320 out of 582 (55\% completion rate) adults who were randomly selected from an online panel (provided by Qualtrics Panel from ClearVoice Research) to be invited to participate in the study. ClearVoice Research has close to 1 million panelists from 120 countries. Online panel members are recruited and regularly verified via SMS or phone. Once they are recruited, they go through a double opt-in process to become a member of online panel. Participation in studies is voluntary, in exchange for cash or gift cards. The sample for the current study was drawn from panel members residing in the U.S (as confirmed by United States Postal Services Verification system). Mean age of the participants was $39.7(S D=12.96)$, and slightly more than half were female (53\%). Majority of the participants either had some college education (26.3\%) or a college degree (39.1\%), followed by high school degree (14.7\%), graduate degree (13.1\%), and technical/vocational degree (5.6\%). 
Participants were randomly assigned to see an SNS profile with either low or high breadth of information. While constructing the SNS profiles that the participants would view, rather than utilizing a profile template that resembled existing SNS platforms like Facebook, Twitter or LinkedIn, we created a fake SNS platform called "mix.r". The reason for this decision was findings from studies suggesting that viewing patterns may vary as a function of a users' familiarity with and expectations from a given web platform (e.g., Nielsen, 2006). As such, our decision to create a fake SNS platform aimed to minimize the potential confounding effects of user differences in familiarity with an existing SNS platform (Figure 1). While creating such a fake SNS profile, we also eliminated any components, such as photos, comments from friends, that may have confounded the effects of breadth and depth of information.

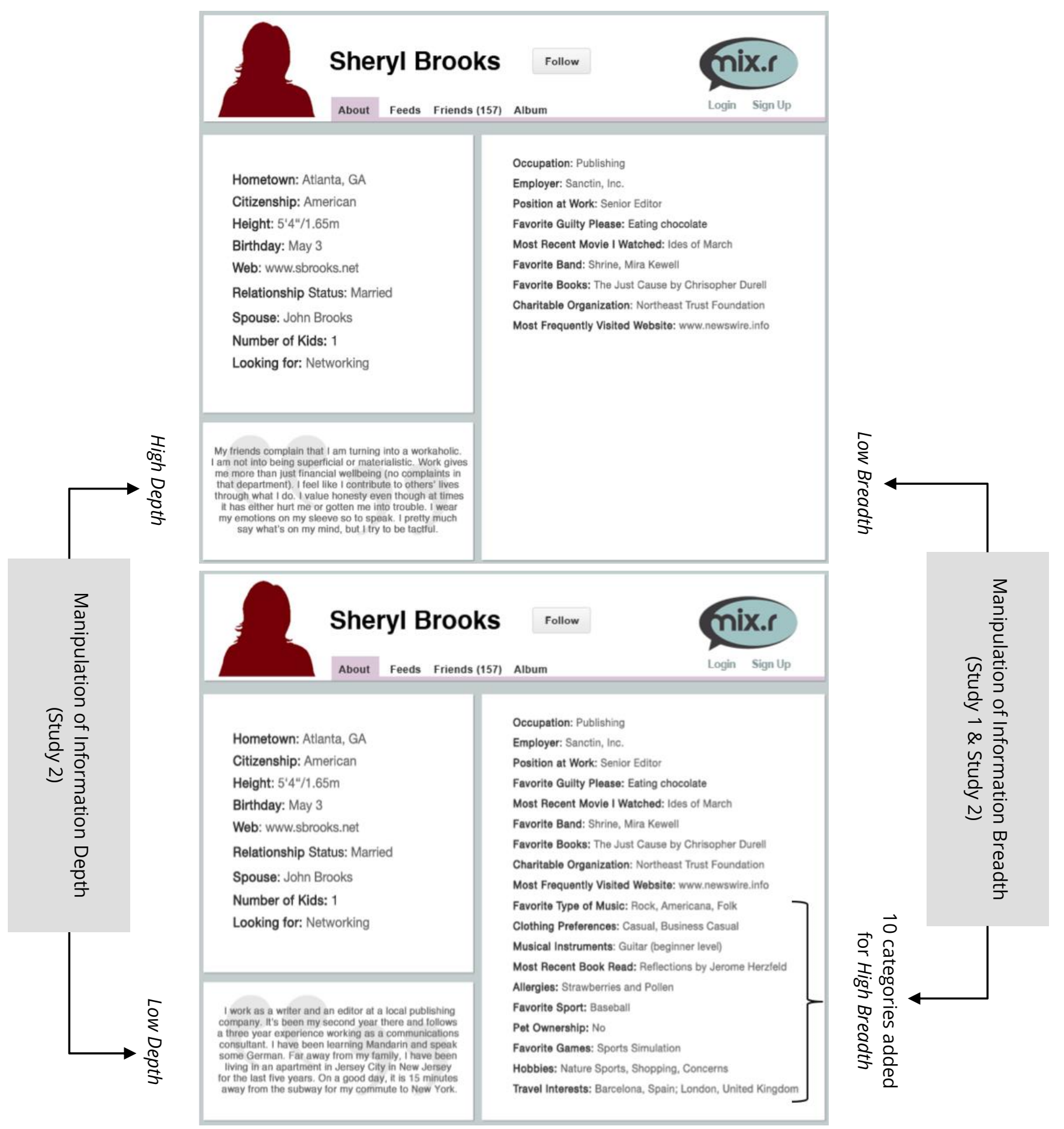

Figure 1. Sample SNS profiles utilized in Study 1 and Study 2. The SNS profile at the top displays an example to an SNS profile of a user containing low breadth and high depth of information.

The SNS profile at the bottom displays an example to an SNS profile of a user containing high breadth and low depth of information. 
To create the profiles, first a library of 78 information categories (e.g., spouse name, profession, favorite food) was compiled by reviewing close to 300 profiles from SNS sites such as Facebook and LinkedIn. Second, for each information category, a fictional profile information item was created. Third, 20 items were randomly selected out of this library to create the low information breadth condition. The high information breadth condition was created by adding 10 additional randomly selected information items to the low information profile.

The decision regarding the respective number of information categories in "low" vs. "high" conditions was based on two related considerations. First, we aimed to create an SNS profile that is consistent with real SNS profiles in terms of information disclosure. While there is limited research in this domain, a content analysis of Facebook profiles found that, on average, users disclose about 26 out of 97 possible information items (Nosko et al., 2010). Second, eye-tracking studies of SNS users indicate that the number of attention points on various SNS sites (e.g., Facebook, MySpace, Twitter) varied between 20 to 30 (excluding navigation and branding related page elements) (Rızvanoğlu \& Öztürk, 2010).

In the first screen of the experiment, participants were presented an instruction indicating that they would review a typical profile page from an SNS. Underneath the instructions, on the same page, the SNS profile was shown full scale as an image (no hyperlinks were provided for further interaction with the profile). On average, the respondents spent 41 seconds reviewing the profiles $(S D=22.75)$. Once they reviewed the profile, respondents would then move onto the next screen which contained items to measure impressions about the profile, uncertainty reduction, and perceived valence of the information shared in the profile.

\section{Measures}

Attributional confidence. In line with previous work on uncertainty reduction (e.g., Orben \& Dunbar, 2017; Tidwell \& Walther, 2002), uncertainty was assessed using a five-item subset of the CL7 Attributional Confidence Scale (Clatterbuck, 1979). Using a scale ranging from strongly disagree (1) to strongly agree (5), the scale assesses the confidence with which respondents could predict the profile owners' behaviors, personality, emotions, and the things they find important (e.g., I can predict well this person's feelings and emotions). The scale had a reliability of $\alpha=.93$.

Interpersonal attraction. Interpersonal attraction was assessed using the Interpersonal Attraction Scale (Montoya \& Horton, 2004). Using a scale ranging from strongly disagree (1) to strongly agree (5), this seven-item scale asks the respondents to indicate how much they would like to further interact with the owner of this profile (e.g., I would like to meet this person). The scale had a reliability of $\alpha=.91$.

\section{Results}

Manipulation check. To ensure that respondents were able to describe the profiles as having low or high breadth of information, we asked them to indicate how much information was contained in the profile they viewed. They responded with a 5-point scale ranging from 1 (very little information) to 5 (a lot of information) $(M=3.53 ; S D=$ 0.95). This manipulation check confirmed that respondents in the low breadth of information condition reported seeing less information than the respondents in the high breadht of information condition $(M=3.33, S D=1.03$ and $M=3.72, S D=0.85$, respectively), $F(1,318)=6.389, p<.001$.

A second manipulation check was conducted to confirm that the additional items utilized for creating the "high breadth" condition did not have an impact on the depth of information revealed in the profile. For this, we asked the respondents to rate the depth of the information shared in the profile, again with a 5-point scale $(M=2.96 ; S D$ $=0.94)$. The analysis suggested no difference between low and high breadth conditions in terms of depth of information $(M=2.89 ; S D=1.01$ and $M=3.03 ; S D=0.89 ; p=.18$, respectively).

Hypothesis tests. Table 1 summarizes ANOVAs comparing the effect of low vs. high breadth of information on the dependent variables. ${ }^{1}$

In line with the prediction of $\mathrm{H} 1$, higher breadth of information led to higher attributional confidence about, $F(1,318)=3.949, p=.048, \eta^{2}=.012$ and interpersonal attraction to the profile owner, $F(1,318)=5.037, p=.026, \eta^{2}$ 
Table 1. Effects of Breadth of Information Presented on a Profile Page (Study 1).

\begin{tabular}{lcccccc}
\hline & Low Breadth & \multicolumn{2}{c}{ High Breadth } & & \\
& $M$ & $(S D)$ & $M$ & $(S D)$ & $F$ & $\eta^{2}$ \\
\hline Attributional Confidence & 3.06 & $(0.82)$ & 3.25 & $(0.82)$ & $3.949^{*}$ & .012 \\
Interpersonal Attraction & 3.24 & $(0.79)$ & 3.43 & $(0.74)$ & $5.037^{*}$ & .016 \\
\hline
\end{tabular}

Note: ${ }^{\star} p<.05,{ }^{\star \star} p<.01$.

Second, using the PROCESS macro in SPSS (Model 4, with a bootstrap approach of 10000 drawings; Hayes, 2013), we tested the model whereby attributional confidence mediates $(\mathrm{H} 2)$ the relationship between breadth of information displayed on a profile page and interpersonal attraction (Figure 2).

Accordingly, attributional confidence fully mediated the relationship between breadth of information and interpersonal attraction $(\beta=.11, p<.048,95 \% \mathrm{Cl}[0.01,0.22]$, for the path from breadth of information in the profile to attributional confidence; and $\beta=.51, p<.001,95 \% \mathrm{Cl}[0.41,0.6]$, for the path from attributional confidence to interpersonal attraction). The mediation model accounted for $28 \%$ of the variation in interpersonal attraction $(p<.001)$.

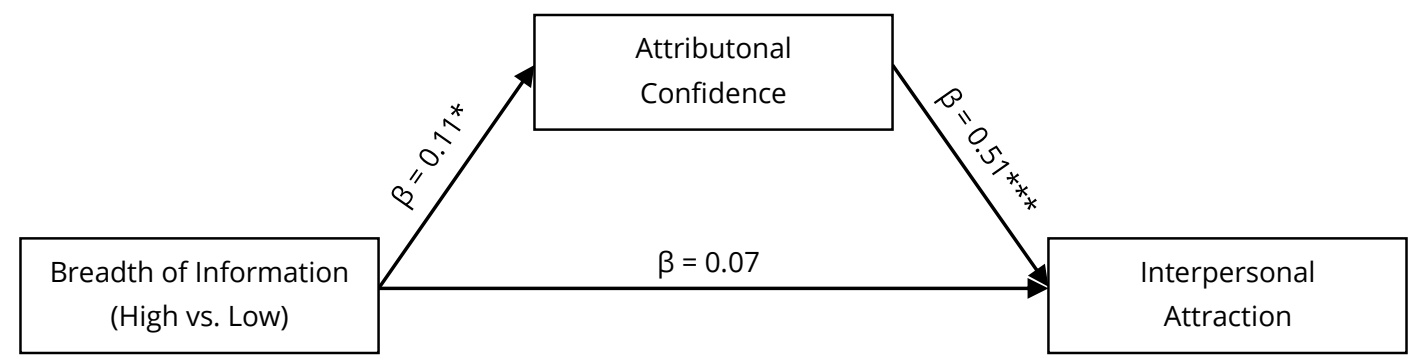

Figure 2. Observed mediation model explaining the relationship between breadth of information, attributional confidence and interpersonal attraction (Study 1). All variables were standardized before running the PROCESS model. The bootstrapped $95 \% \mathrm{Cls}$ for the direct effect of breadth on interpersonal attraction were $-0.03,0.16$. The bootstrapped $95 \% \mathrm{Cls}$ for the indirect effect of breadth on interpersonal attraction were $0.00,0.12 .{ }^{*} p<.05,{ }^{* *} p<.01, * * * p<.001$.

\section{Discussion}

In study 1, our primary goal was to establish the impact of breadth of information shared on a profile page on viewers' decisions about the profile owner. Our analyses confirmed that when the breadth of information on a profile page was higher, viewers were more confident about the attributions they could make about the profile owner and this, in turn, increased interpersonal attraction to profile owner.

In the second study, we introduce depth of information as another dimension of self-disclosure. With a new sample, we investigate the respective and joint effects of breadth and depth of information on profile viewers' attributional confidence about and interpersonal attraction to the profile owner.

\section{Study 2}

\section{Method}

Participants and procedure. An online sample of 537 out of 1543 adult respondents completed the study. As in Study 1, the participants, residing in the U.S., were randomly selected from the online panel provided by Qualtrics Panel from ClearVoice Research ${ }^{\circledR}$. Mean age of the respondents was $46.9(S D=12.18)$, and half were female (49.7\%). Majority of the participants had some college education (30.4\%) or had a college degree (27.4\%), followed by high school degree (21.2\%), technical/vocational degree (9.3\%), graduate degree (7.3\%). There were no overlap between the two studies in terms of the IP addresses of the study participants. 
The study employed a 2 (low vs. high breadth of information) $\times 2$ (low vs. high depth of information) design. Participants were randomly assigned to one of the conditions. The manipulation of breadth of information was identical with Study 1. Additionally, in the second study, depth was manipulated through a short biographical text constructed from the same library of information items used for Study 1 (Figure 1). On average, participants viewed the profiles for 58 seconds $(S D=33.89)$.

Two pilots with independent samples were conducted to make sure that viewers were able to differentiate the level of depth in the profiles they saw. In the first pilot, 26 students rated the depth level of the biographical texts using a three-point scale $(M=1.42$ and $M=2.27$ respectively for low and high depth, $p<.001)$. Next these biographical texts were inserted into the profiles used in Study 1 and were pilot tested with a separate sample of 133 participants obtained from the Qualtrics Panel. Analysis confirmed that profile viewers clearly distinguished between low vs. high depth profiles as intended $(M=1.37$ and $M=2.27$, respectively, $p<.001)$.

The experimental procedure and the measures of the dependent variables (attributional confidence and interpersonal attraction) were identical with Study 1, described above.

\section{Results}

Table 2 summarizes the results of the $2 \times 2$ ANOVAs employing breadth and depth of information as the independent variables predicting attributional confidence and interpersonal attraction. Accordingly, in line with findings from Study 1 regarding $\mathrm{H1}$, breadth of information increased interpersonal attraction, $F(1,532)=5.386, p$ $=.021, \eta^{2}=.01$. However, breadth of information no longer significantly predicted attributional confidence, $F(1,532)$ $=0.467, p=.495$. In line with $\mathrm{H} 3$, while information with higher depth increased attributional confidence among profile viewers, $F(1,532)=12.090, p<.001, \eta^{2}=.022$, it had a negative impact on interpersonal attraction $F(1,532)$ $=4.210, p=.041, \eta^{2}=.008 .^{2}$

Table 2. Effects of Breadth and Depth of Information Presented on a Profile Page (Study 2).

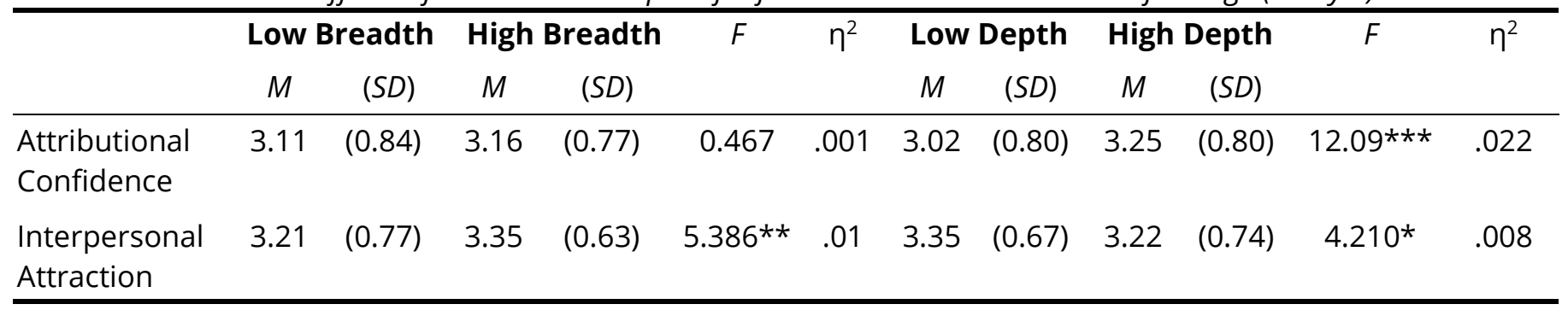

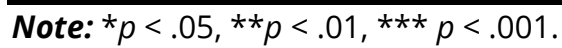

With respect to the RQ1, there was a significant interaction between breadth and depth of information in predicting attributional confidence about the profile owner, $F(1,532)=12.365, p<.001, \eta^{2}=.023$. On the other hand, the interaction between breadth and depth of information did not significantly predict interpersonal attraction, $F(1,532)=0.269, p=.604$.

In the light of this finding, an additional moderated mediation analysis was conducted using the PROCESS macro in SPSS (Model 8, with a bootstrap approach of 10000 drawings) to test the RQ1, H3, and H4. This model replicates the mediation model tested in Study 1 with two additions. First, following the findings from the ANOVA described above, the model allows for interaction between breadth and depth of information in predicting the mediator variable (i.e., attributional confidence). Second, the model tests the respective direct and indirect effects of breadth and depth of information on interpersonal attraction (Figure 3).

After controlling for depth and attributional confidence, breadth of information continues to have a significant direct effect on interpersonal attraction $(\beta=0.09, p=.028,95 \% \mathrm{Cl}[0.01,0.17])$. Also, after controlling for breadth, depth of information has influence on interpersonal attraction in two distinct ways. On the one hand, depth of information increases interpersonal attraction indirectly by increasing attributional confidence $(\beta=0.14, p<.001$, $95 \% \mathrm{Cl}[0.06,0.23]$, for the path from depth to attributional confidence; and $\beta=0.28, p<.001,95 \% \mathrm{Cl}[0.20,0.36]$, for the path from attributional confidence to interpersonal attraction). However, higher depth of information 
shared on a profile has a direct negative influence on interpersonal attraction $(\beta=-0.13, p<.001,95 \% \mathrm{Cl}[-0.21$, 0.05]).

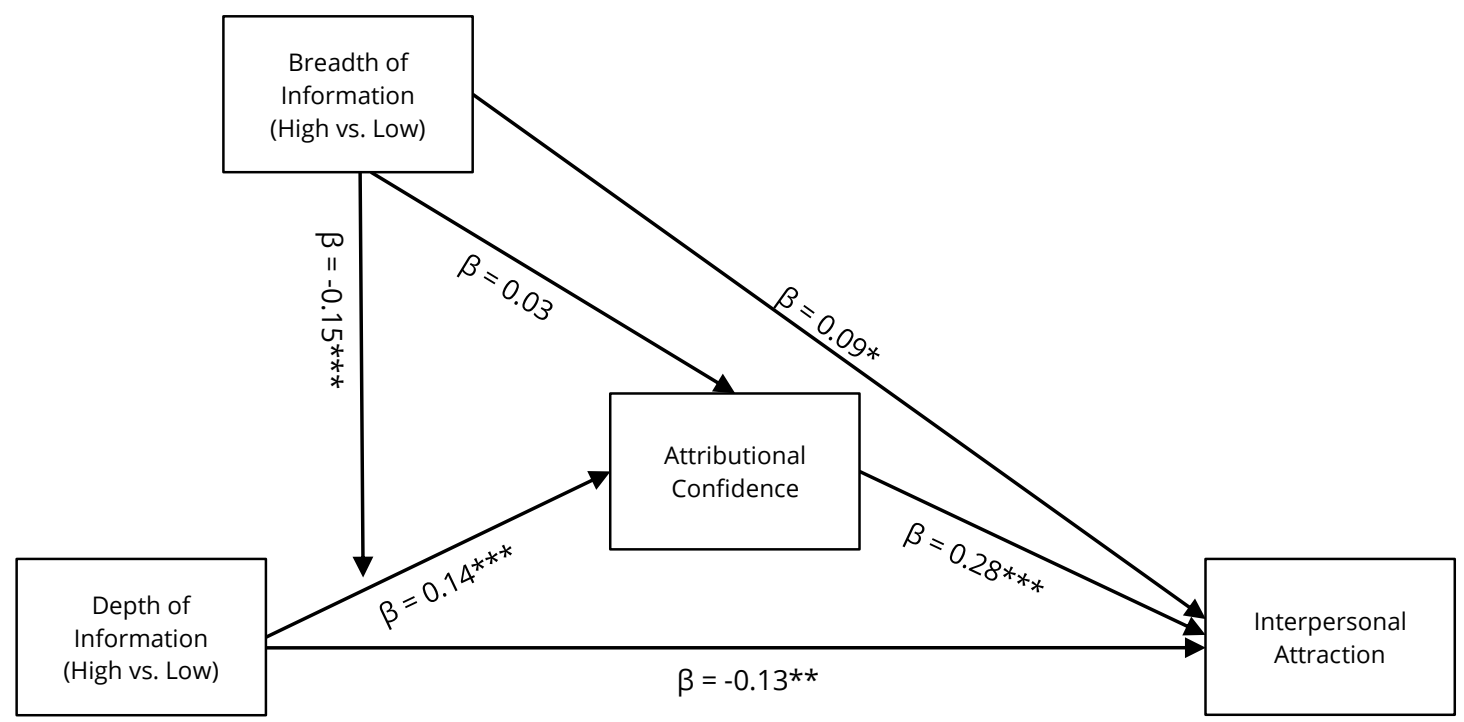

Figure 3. Observed moderated mediation model explaining the relationship between information breadth and depth, attributional confidence and interpersonal attraction (Study 2). All variables were standardized before running the

PROCESS model. ${ }^{*} p<.05, * * p<.01, * * * p<.001$. Model 8 in the PROCESS macro also estimates the interaction between breadth and depth on attraction. This interaction was not statistically significant, $\beta=0.02, p=.64$.

To simplify the presentation of information, the path for this coefficient is not included in the figure.

Finally, in relation to RQ1, as depicted in Figure 4 , the interaction $(\beta=-0.15, p<.001,95 \% \mathrm{Cl}[-0.23,-0.07])$ between breadth and depth of disclosure was such that when users shared higher breadth of information, higher depth did not contribute to attributional confidence but when breadth of information was lower, attributional confidence increased as depth of information increased.

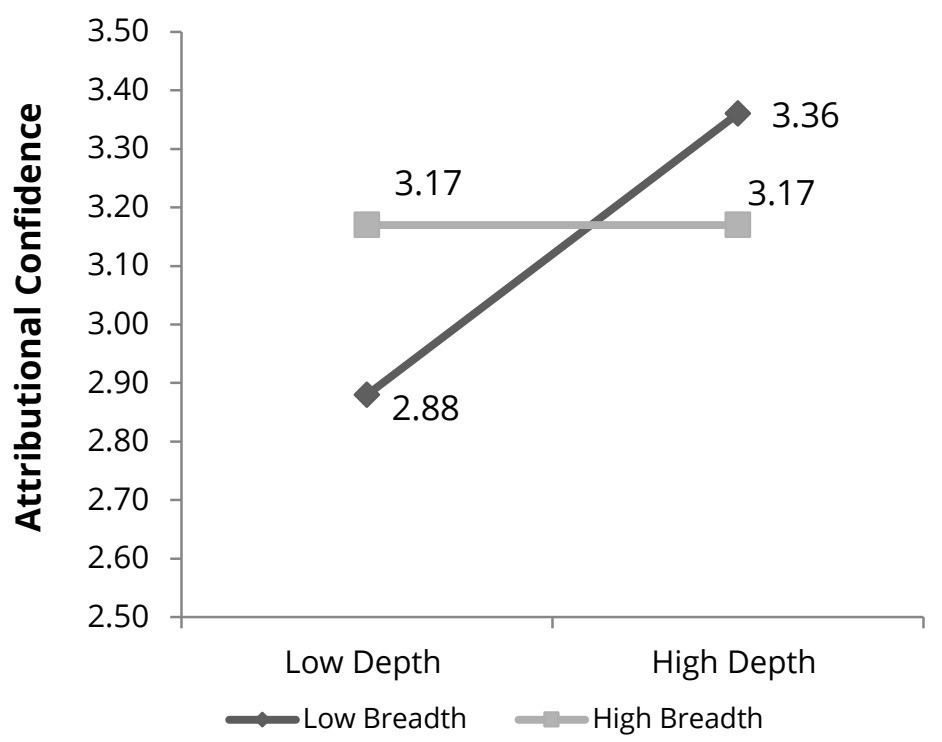

Figure 4. Interaction between depth and breadth of information.

\section{Discussion}

While Study 1 tested the isolated effect of breadth of information displayed on an SNS profile on attributional confidence about and interpersonal attraction to the profile owner, Study 2 aimed to investigate the respective effects of both breadth and depth of information.

With respect to the effect of breadth of information, one key difference we observed was that information breadth was no longer a significant predictor of attributional confidence when depth was added as a second dimension of disclosure in Study 2. However, breadth of information remained as a significant predictor of interpersonal 
attraction. As for depth of information, our analyses underlined a direct and an indirect effect on interpersonal attraction. Directly, disclosure of more intimate information reduced interpersonal attraction. At the same time, when breadth of information disclosed was low, disclosure of intimate information contributed positively to interpersonal attraction via increasing attributional confidence.

\section{General Discussion}

In its "how to" guide to making friends on Facebook, the wikiHow platform (n.d.) advises its readers to "keep it personal without being so personal it turns anyone off or becomes too much information for the public forum." This advice about Facebook etiquette underlines the increasing role that self-disclosure through SNS profiles may play in formation of relationships. In this light, a substantial body of research has focused on questions related to predictors and effects of self-disclosure in SNSs. Yet, systematic evidence on how different dimensions of disclosure influence relational outcomes in zero-acquaintance situations within the context of SNSs is limited. This article reports two experiments that aimed to address elementary questions regarding the respective impact of breadth and depth of disclosure on interpersonal attraction within the context of SNSs.

In the first experiment, in line with the premise of the URT, we found that increasing breadth of information presented in an SNS profile enhances viewers' attributional confidence, which in turn, increases interpersonal attraction to the profile owner. The aim of the second experiment was to investigate how varying degrees of not only breadth of information but also depth level of the information would influence interpersonal attraction. First, we predicted and showed that increasing depth of information would positively contribute to interpersonal attraction by increasing attributional certainty. Second, we predicted and showed that despite its potential contribution to increasing certainty, disclosure of intimate information on an SNS profile may also hurt interpersonal attraction.

These findings presented with respect to the impact of breadth and depth of information on interpersonal attraction has important implications for the application of URT in SNS contexts. URT indicates that in early stages of interpersonal relationships dyads will be motivated to predict each other's attitudes and behavior and determine whether they would like to pursue further interactions with each other. Accordingly, in first encounters, increasing exchange of information will reduce uncertainty (Axiom 1) which will, in turn, increase liking among partners (Axiom 7) (Berger \& Calabrese, 1975). Typically, in face-to-face interactions, uncertainty reduction entails reciprocal disclosure of information between partners. Similarly, earlier research on uncertainty reduction in CMC contexts suggests that interactive methods of decreasing uncertainty will be most effective (e.g., Antheunis et al. 2010). Yet, in SNS contexts, such as when a user peruses a public profile of another person, interactive means of reducing uncertainty will not be immediately available. In such situations, self-disclosure will not be dyadic, potentially altering norms and expectations about interpersonal dynamics (Hancock \& Dunham, 2001). Our findings regarding the mediating effects of attributional confidence (as a commonly utilized operationalization of uncertainty) on the relationship between levels of disclosure and interpersonal attraction imply that despite this difference, the premise of URT that decreasing the level of uncertainty will similarly enhance interpersonal attraction in SNS settings.

A second implication of this finding concerns assumptions about how impressions are formed in zeroacquaintance situations. Namely, research on first-impressions indicate that individuals rely mostly on visuals cues (e.g., physical attractiveness, gestures) to quickly make judgments about others (e.g., Ambady \& Rosenthal, 1993; Kraus \& Keltner, 2009). Findings from our study implies that a similar tendency might be in place in using disclosed textual information to make quick judgments about others in SNSs. That is, the increase in attributional confidence (and consequently interpersonal attraction) as a function of breadth of information suggests that despite only briefly reviewing the SNS profiles (average of 41 seconds) participants were able to utilize the profile information to make judgments about the profile owners.

At the same time, these findings also underline that the information sharing approaches used by a profile owner to decrease uncertainty may be critical to whether the uncertainty reduction will translate to favorable relational outcomes. Specifically, sharing intimate information, despite decreasing uncertainty, may be detrimental to building good first impressions because they are deemed inappropriate in early stages of a relationship. 
This interpretation of our findings is in line with a recent study by Orben \& Dunbar (2017), which reports that perceived appropriateness mediates the relationship between disclosure depth and social attraction on Facebook. In this respect, our findings provide key support to existing discussions about implications of intimate disclosure on SNSs given the extent to which their open structure can lead to context collapses whereby intimate information shared by users become, intentionally or accidentally, available publicly (Bazarova, 2012). Specifically, within the context of use of SNSs for expansion of social networks, these results underline that such context collapses may be counterproductive to relationship initiation.

Another possible explanation of why disclosure of intimate information may lead to lower interpersonal attraction concerns the content of intimate information. Later revisions of the URT predict that the extent to which reduction in uncertainty can aid interpersonal attraction depends on a process of attribute evaluation about the discloser of the information. Specifically, reduction in uncertainty would enhance attraction only when the recipients perceive the information positively (Norton et al., 2007; Sunnafrank, 1986). In our study, whereas the low depth condition contained relatively innocuous information about profession, employment history and spoken languages, the high depth condition contained information about personal values, work ethics, and emotions of the profile owner. It is possible that some of this information was perceived negatively by recipients (over and above their inappropriateness). Given these considerations, future research utilizing URT in SNS contexts should investigate how viewers' evaluation of the valence and appropriateness of intimate information may interact with reduction in uncertainty in predicting interpersonal attraction.

A unique contribution of the findings presented in this article pertains to the respective impact of breadth and depth of disclosure on interpersonal attraction in SNS contexts. The first key finding is that after controlling for depth of information, breadth of information does not have an impact on attributional certainty. Second, we focused on the impact of the interaction between breadth and depth of information on attributional confidence about and interpersonal attraction to a profile owner. While the interaction between depth and breadth did not significantly predict interpersonal attraction, our findings indicated that depth of information had an impact on attributional confidence only when a profile contained low breadth of information. Both of these results, albeit indirectly, have implications for application of models such as the Realistic Accuracy Model (Beer \& Brooks, 2011; Funder, 1995; Funder, 2012) to SNSs. According to this model, availability of good information (i.e., high breadth and high relevance for judgments) may have an additive effect on accuracy of the judgments individuals make about others. Our findings, however, imply that, at least from the standpoint of viewers' own confidence about their ability to make a judgment about the profile owner, increasing both depth and breadth does not contribute to enhancing attributional confidence. It is possible that this may be due to users' involvement and consequently amount of time and resources allocated to viewing the SNS profile of a stranger. Namely, to the extent that SNS users make judgments quickly about whether to further peruse (or interact with) a profile, presenting high breadth of information may have a crowd-out effect that reduces the resources (i.e., time and effort) available for the viewer to process more evaluative potential of intimate information. While this study presents first elementary evidence for such potential impact of overloading SNS profiles with information, further studies would be needed to understand the point after which adding more information does not contribute to attributional confidence, but also SNS contexts and user characteristics that may reduce or enhance ability and motivation to process more information.

From an applied standpoint, these findings imply that increasing the diversity of information that one discloses, but doing so without sharing very intimate information or being selective in terms of the audience of the disclosed intimate information, may be the strategically most efficient way for users trying to build better first impressions on SNSs. It should be noted that this applied implication is not merely about "friending" others on SNSs. While expanding one's network is one of the potential uses of SNSs, the most common use of SNSs like Facebook is to support existing (weak and strong) networks. Nevertheless, as discussed in the introduction, there is now increasing anecdotal and empirical evidence suggesting that SNS profiles are used for forming impressions not only about potential friends but also potential employees, students, and teammates (e.g., Brown \& Vaughn, 2011; Hoek et al. 2016; Somers, 2017). Setting aside ethical issues (Black \& Johnson, 2012), the prevalence of such practices increases the importance of understanding how SNS profiles are used for forming first impressions. In this respect, the findings from this study are valuable particularly because of the approach we adopted in testing the respective impact of breadth and depth of information disclosure. Specifically, rather than using a familiar SNS platform (like Facebook or LinkedIn) we developed a generic (fake) SNS profile page with commonly utilized profile elements and information categories (e.g., number of friends). This not only reduces the likelihood that user 
familiarity with a given SNS platform will interfere with how profile information is processed but also increases the generalizability of findings to different contexts and potential uses of SNSs. On the other hand, given recent research suggesting that user motivations (e.g., seeking friends, seeking romantic relationships, evaluating another person as a profession) influence SNS profile viewing strategies (Scott \& Hand, 2016), future work should investigate how such motivations influence response to dimensions of disclosure.

Relatedly, in considering the possibility that varying levels of breadth and depth may influence the extent to which SNS users utilize the available information for evaluative purposes, we should note that self-disclosure not only serves an informational function but also has an entertainment value (Lin, Levordashka, Utz, 2016; Utz, 2015). In this respect, it is possible, for example, that users seeking to expand their network via SNSs will differ from those who use SNSs for satisfying social curiosity in terms of how they utilize the available information. Future work would need to investigate how users' motivation (e.g., whether they anticipate or motivated for future involvement, whether they are oriented towards using SNSs for relationship initiation) influence the extent to which they pay attention to the intimate information that may have higher evaluative value.

\section{Limitations}

First, it should be noted that the measure of interpersonal attraction (Montoya \& Horton, 2004) we utilized is a behavioral attraction measure (e.g., I would like to meet this person). As such, it may be particularly responsive to levels of attributional confidence about the profile owner. This is mainly because, as predicted by URT (Axiom 1), as attributional confidence increases (i.e., uncertainty declines) the chances that dyads will seek further opportunities to exchange information will also increase. In this respect, testing the respective influence of breadth, depth and uncertainty on measures of affective attraction (e.g., Byrne, 1971) will be beneficial in terms of understanding the impact of information sharing within zero-acquaintance situations in SNS contexts.

Another potential limitation of our study concerns the operationalization of breadth of information. As discussed above, our manipulation of breadth of information entailed creating a low breadth condition using 20 categories of textual information items and creating the high breadth condition by adding another 10 categories. As such, this manipulation may have resulted not only in an increase in breadth of information but also the amount (i.e., number of statements about self) of information presented in the profiles. With this caveat in mind, however, our findings not only clarify the possible confusions in the literature that suggests that type of information present on a profile (such as photos, Limperos et al., 2014; Utz, 2010) may confound with self-disclosure on SNSs but also provides first insights as to how different dimensions of self-disclosure needs to be accounted for in understanding the potential impact of self-disclosure on interpersonal attraction in zero-acquaintance situations on SNSS.

\section{Notes}

1. We also tested whether participant gender influenced attributional confidence and interpersonal attraction. Participant gender had no direct effect on either of the variables and did not significantly interact with the breadth manipulation. Hence, participant gender will not be further reported for Study 1.

2. We also tested whether participant gender influenced attributional confidence and interpersonal attraction. Participant gender had no direct effect on either one of the variables and did not significantly interact with depth or breadth manipulations. Hence, participant gender will not be further reported for Study 2.

\section{References}

Afifi, W. A., \& Burgoon, J. K. (2000). The impact of violations on uncertainty and the consequences for attractiveness. Human Communication Research, 26, 203-233. https://doi.org/10.1111/j.1468-2958.2000.tb00756.x

Ajzen, I. (1974). Effects of information on interpersonal attraction: Similarity versus affective value. Journal of Personality and Social Psychology, 29, 374-380. https://doi.org/10.1037/h0036002

Altman, I., \& Taylor, D. (1973). Social penetration: The development of interpersonal relationships. New York: Holt, 
Rinehart and Winston.

Ambady, N., \& Rosenthal, R. (1993). Half a minute: Predicting teacher evaluations from thin slices of nonverbal behavior and physical attractiveness. Journal of Personality and Social Psychology, 64, 431-441.

https://doi.org/10.1037/0022-3514.64.3.431

Anderson, S. P., \& de Palma, A. (2009). Information congestion. RAND Journal of Economics, 4, 688-709. https://doi.org/10.1111/j.1756-2171.2009.00085.x

Anderson, S. P., \& de Palma, A. (2012). Competition for attention in the Information (overload) Age. RAND Journal of Economics, 43, 1-25. https://doi.org/10.1111/j.1756-2171.2011.00155.x

Antheunis, M. L., Valkenburg, P. M., \& Peter, J. (2010). Getting acquainted through social network sites: Testing a model of online uncertainty reduction and social attraction. Computers in Human Behavior, 26, 100-109.

https://doi.org/10.1016/j.chb.2009.07.005

Archer, R. L., \& Berg, J. H. (1978). Disclosure reciprocity and its limits: A reactance analysis. Journal of Experimental Social Psychology, 14, 527-540. https://doi.org/10.1016/0022-1031(78)90047-1

Attrill, A., \& Jalil, R. (2011). Revealing only the superficial me: Exploring categorical self-disclosure online. Computers in Human Behavior, 27, 1634-1642. https://doi.org/10.1016/j.chb.2011.02.001

Baruh, L., \& Cemalcılar, Z. (2015). Rubbernecking effect of intimate information on Twitter: When getting attention works against interpersonal attraction. Cyberpsychology, Behavior, and Social Networking, 18, 506-513. https://doi.org/10.1089/cyber.2015.0099

Baruh, L., Cemalcılar, Z., Bisson, C., \& Chisik, Y. (2017). First impressions on social network sites: Impact of selfdisclosure breadth on Attraction. In A. Skarzauskiene \& N. Gudeliene (Eds.), Proceedings of the 4th European Conference on Social Media (pp. 54-62). Vilnius: Academic Conferences and Publishing International Limited.

Baym, N. K. (2010). Personal connections in a digital age. Cambridge: Polity Press.

Bazarova, N. N. (2012). Public intimacy: Disclosure interpretation and social judgments on Facebook. Journal of Communication, 62, 815-832. https://doi.org/10.1111/j.1460-2466.2012.01664.x

Bazarova, N. N., \& Choi, Y. H. (2014). Self-disclosure in social media: Extending the functional approach to disclosure motivations and characteristics on social network sites. Journal of Communication, 64, 635-657. https://doi.org/10.1111/jcom.12106

Bazarova, N. N., Taft, J. G., Choi, Y. H., \& Cosley, D. (2013). Managing impressions and relationships on Facebook: Self-presentational and relational concerns revealed through the analysis of language style. Journal of Language and Social Psychology, 32, 121-141. https://doi.org/10.1177/0261927X12456384

boyd, D., Perez, J., \& Loyola, V. (2008). Facebook's privacy trainwreck. Convergence: The International Journal of Research into New Media Technologies, 14, 13-20. https://doi.org/10.1177/1354856507084416

Beer, A., \& Brooks, C. (2011). Information quality in personality judgment: The value of personal disclosure. Journal of Research in Personality, 45, 175-185. https://doi.org/10.1016/j.jrp.2011.01.001

Beer, A., \& Watson, D. (2010). The effects of information and exposure on self-other agreement. Journal of Research in Personality, 44, 38-45. https://doi.org/10.1016/j.jrp.2009.10.002

Berger, C. R., \& Calabrese, R. J. (1975). Some explorations in initial interaction and beyond: Toward a developmental theory of interpersonal communication. Human Communication Research, 1, 99-112. https://doi.org/10.1111/j.1468-2958.1975.tb00258.x

Black, S. L., \& Johnson, A. F. (2012). Employers' use of social networking sites in the selection process. Journal of Social Media in Society, 1, 8-28.

Bouchillon, B. C., \& Gotlieb, M. R. (2016). Making them count: Facebook sociability for optimizing the accumulation of social capital. Social Science Computer Review, 35, 299-318.

https://doi.org/10.1177/0894439315626422

Brown, V. R., \& Vaughn, E. D. (2011). The writing on the (Facebook) wall: The use of social networking sites in hiring decisions. Journal of Business and Psychology, 26, 219-225. https://doi.org/10.1007/s10869-011-9221-x 
Byrne, D. (1971). The attraction paradigm. New York: Academic Press

Chaikin, A. L., \& Derlega, V. J. (1974). Variables affecting the appropriateness of self-disclosure. Journal of Consulting and Clinical Psychology, 42, 588-593. https://doi.org/10.1037/h0036614

Chen, Y. C., Shang, R. A., \& Kao, C. Y. (2009). The effects of information overload on consumers' subjective state towards buying decision in the internet shopping environment. Electronic Commerce Research and Applications, 8 , 48-58. https://doi.org/10.1016/j.elerap.2008.09.001

Choi, Y. H., \& Bazarova, N. N. (2015). Self-disclosure characteristics and motivations in social media: Extending the functional model to multiple social network sites. Human Communication Research, 41, 480-500.

https://doi.org/10.1111/hcre.12053

Clatterbuck, G. W. (1979). Attributional confidence and uncertainty in initial interaction. Human Communication Research, 5, 147-157. https://doi.org/10.1111/j.1468-2958.1979.tb00630.x

Collins, N. L., \& Miller, L. C. (1994). Self-disclosure and liking: A meta-analytic review. Psychological Bulletin, 116, 457-475. https://doi.org/10.1037/0033-2909.116.3.457

Derlega, V. J., Winstead, B. A., \& Greene, K. (2008). Self-disclosure and starting a close relationship. In S. Sprecher, A. Wenzel, \& J. Harvey (Eds.), Handbook of relationship initiation (pp. 153-174). New York: Psychology Press.

Eppler, M. J., \& Mengis, J. (2004). The concept of information overload: A review of the literature from organization science, accounting, MIS, and related disciplines. The Information Society, 20, 325-344.

https://doi.org/10.1080/01972240490507974

Funder, D. C. (1995). On the accuracy of personality judgment: A realistic approach. Psychological Review, 102, 652-670. https://doi.org/10.1037/0033-295X.102.4.652

Funder, D. C. (2012). Accurate personality judgment. Current Directions in Psychological Science, 21, 177-182. https://doi.org/10.1177/0963721412445309

Gibbs, J. L., Ellison, N. B., \& Heino, R. D. (2006). Self-presentation in online personals: The role of anticipated future interaction, self-disclosure, and perceived success in internet dating. Communication Research, 33, 152177. https://doi.org/10.1177/0093650205285368

Greene, K., Derlega, V. J., \& Mathews, A. (2006). Self-disclosure in personal relationships. In A. Vangelisti \& D. Perlman (Eds.), The Cambridge handbook of personal relationships (pp. 409-427). Cambridge, UK: Cambridge University Press.

Hancock, J. T., \& Dunham, P. J. (2001). Impression formation in computer-mediated communication revisited: An analysis of the breadth and intensity of impressions. Communication Research, 28, 325-347.

https://doi.org/10.1177/009365001028003004

Hayes, A. (2013). Introduction to mediation, moderation, and conditional process analysis. New York: The Guilford Press.

Herring, S. C. (2003). Gender and power in online communication. In J. Holmes \& M. Meyerhoff (Eds.), The handbook of language and gender (pp. 202-228). Oxford: Blackwell Publishers.

Hoek, J., O'Kane, P., \& McCracken, M. (2016). Publishing personal information online: How employers' access, observe and utilise social networking sites within selection procedures. Personnel Review, 45(1), 67-83.

https://doi.org/10.1108/PR-05-2014-0099

Ignatius, E., \& Kokkonen, M. (2007). Factors contributing to verbal self-disclosure. Nordic Psychology, 59, 362-391. https://doi.org/10.1027/1901-2276.59.4.362

Jackson, T. W., \& Farzaneh, P. (2012). Theory-based model of factors affecting information overload. International Journal of Information Management, 32, 523-532. https://doi.org/10.1016/j.ijinfomgt.2012.04.006

Jiang, L. C., Bazarova, N. N., \& Hancock, J. T. (2011). The disclosure-intimacy link in computer-mediated communication: An attributional extension of the hyperpersonal model. Human Communication Research, 37, 5877. https://doi.org/10.1111/j.1468-2958.2010.01393.x

Jin, S.-A. A. (2013). Peeling back the multiple layers of Twitter's private disclosure onion: The roles of virtual 
identity discrepancy and personality traits in communication privacy management on Twitter. New Media \& Society, 15, 813-833. https://doi.org/10.1177/1461444812471814

Joinson, A. N. (2001). Self-disclosure in computer-mediated communication: The role of self-awareness and visual anonymity. European Journal of Social Psychology, 31, 177-192. https://doi.org/10.1002/ejsp.36

Jones, Q., Moldovan, M., Raban, D., \& Butler, B. (2008). Empirical evidence of information overload constraining chat channel community interactions. In Proceedings of the ACM 2008 Conference on Computer Supported Cooperative Work - CSCW '08 (pp. 323-332). https://doi.org/10.1145/1460563.1460616

Jones, Q., Ravid, G., \& Rafaeli, S. (2004). Information overload and the message dynamics of online interaction spaces: A theoretical model and empirical exploration. Information Systems Research, 15, 194-211. https://doi.org/10.1287/isre.1040.0023

Kashian, N., Jang, J. woo, Shin, S. Y., Dai, Y., \& Walther, J. B. (2017). Self-disclosure and liking in computermediated communication. Computers in Human Behavior, 71, 275-283. https://doi.org/10.1016/j.chb.2017.01.041

Katzer, J., \& Fletcher, P. T. (1992). The information environment of managers. Annual Review of Information Science and Technology, 27, 227-263.

Koroleva, K., Krasnova, H., \& Günther, O. (2010). "Stop spamming me!" - Exploring information overload on Facebook. In Proceedings of the Sixteenth Americas Conference on Information Systems (AMCIS) (paper 447).

Kraus, M. W., \& Keltner, D. (2009). Signs of socioeconomic status: A thin-slicing approach. Psychological Science, 20, 99-106. https://doi.org/10.1111/j.1467-9280.2008.02251.x

Lampe, C., Ellison, N., \& Steinfield, C. (2006). A Face(book) in the crowd: Social searching vs. social browsing. In Proceedings 20th Conference on Computer Supported Cooperative Work (pp. 167-170). New York: ACM Press.

Ledbetter, A. M., Mazer, J. P., DeGroot, J. M., Meyer, K. R., Mao, Y., \& Swafford, B. (2011). Attitudes toward online social connection and self-disclosure as predictors of Facebook communication and relational closeness. Communication Research, 38, 27-53. https://doi.org/10.1177/0093650210365537

Limperos, A. M., Tamul, D. J., Woolley, J. K., Spinda, J. S. W., \& Sundar, S. S. (2014). "It's not who you know, but who you add:" An investigation into the differential impact of friend adding and self-disclosure on interpersonal perceptions on Facebook. Computers in Human Behavior, 35, 496-505. https://doi.org/10.1016/j.chb.2014.02.037

Lin, R., Levordashka, A., \& Utz, S. (2016). Ambient intimacy on Twitter. Cyberpsychology: Journal of Psychosocial Research on Cyberspace, 10(1), article 6. https://doi.org/10.5817/CP2016-1-6

Lin, R., \& Utz, S. (2017). Self-disclosure on SNS: Do disclosure intimacy and narrativity influence interpersonal closeness and social attraction? Computers in Human Behavior, 70, 426-436.

https://doi.org/10.1016/j.chb.2017.01.012

Marwick, A. E., \& boyd, d. (2011). I tweet honestly, I tweet passionately: Twitter users, context collapse, and the imagined audience. New Media \& Society, 13, 114-133. https://doi.org/10.1177/1461444810365313

McKenna, K. Y. A., Green, A. S., \& Gleason, M. E. J. (2002). Relationship formation on the Internet: What's the big attraction? Journal of Social Issues, 58, 9-31. https://doi.org/10.1111/1540-4560.00246

Merkle, E. R., \& Richardson, R. (2000). Digital dating and virtual relating: Conceptualizing computer mediated romantic relationships. Family Relations, 49, 187-192. https://doi.org/10.1111/j.1741-3729.2000.00187.x

Montoya, R. M., \& Horton, R. S. (2004). On the importance of cognitive evaluation as a determinant of interpersonal attraction. Journal of Personality and Social Psychology, 86, 696-712. https://doi.org/10.1037/00223514.86.5.696

Nelson, M. R. (1994). We have the information you want, but getting it will cost you! Crossroads, 1(1), 11-15. https://doi.org/10.1145/197177.197183

Nguyen, M., Bin, Y. S., \& Campbell, A. (2012). Comparing online and offline self-disclosure: A systematic review. Cyberpsychology, Behavior, and Social Networking, 15, 103-111. https://doi.org/10.1089/cyber.2011.0277

Nielsen, J. (2006). F-shaped pattern for reading web content. Retrieved from

www.useit.com/alertbox/reading_pattern.html 
Norton, M. I., Frost, J. H., \& Ariely, D. (2007). Less is more: The lure of ambiguity, or why familiarity breeds contempt. Journal of Personality and Social Psychology, 92, 97-105. https://doi.org/10.1037/0022-3514.92.1.97

Nosko, A., Wood, E., \& Molema, S. (2010). All about me: Disclosure in online social networking profiles: The case of Facebook. Computers in Human Behavior, 26, 406-418. https://doi.org/10.1016/j.chb.2009.11.012

Orben, A. C., \& Dunbar, R. I. M. (2017). Social media and relationship development: The effect of valence and intimacy of posts. Computers in Human Behavior, 73, 489-498. https://doi.org/10.1016/j.chb.2017.04.006

Pratt, L., Wiseman, R. L., Cody, M. J., \& Wendt, P. F. (1999). Interrogative strategies and information exchange in computer-mediated communication. Communication Quarterly, 47(1), 46-66.

https://doi.org/10.1080/01463379909370123

Perry, V. G., \& Blumenthal, P. M. (2012). Understanding the fine print: The need for effective testing of mandatory mortgage loan disclosures. Journal of Public Policy \& Marketing, 31, 305-312. https://doi.org/10.1509/jppm.12.055

Reis, H. T., \& Patrick, B. C. (1996). Attachment and intimacy: Component processes. In E. T. Higgins \& A. W. Kruglanski (Eds.) Social psychology: Handbook of basic principles (pp. 523-563). New York: Guilford Press.

Rızvanoğlu, K., \& Öztürk, Ö. (2010). A close look at the phenomenon: an eye tracking study on the usability of the profile pages in social networking sites. In 7th International Symposium of Interactive Media Design (pp. 1-12). Istanbul.

Schouten, A. P., Valkenburg, P. M., \& Peter, J. (2009). An experimental test of processes underlying self-disclosure in computer-mediated communication. Cyberpsychology: Journal of Psychosocial Research on Cyberspace, 3(2), article 3. Retrieved from https://cyberpsychology.eu/article/view/4227/3270

Scott, G. G., \& Hand, C. J. (2016). Motivation determines Facebook viewing strategy: An eye movement analysis. Computers in Human Behavior, 56, 267-280. https://doi.org/10.1016/j.chb.2015.11.029

Scott, G. G., Sinclair, J., Short, E., \& Bruce, G. (2014). It's not what you say, it's how you say it: Language use on facebook impacts employability but not attractiveness. Cyberpsychology, Behavior, and Social Networking, 17, 562566. https://doi.org/10.1089/cyber.2013.0584

Smith, A. (2011). Why Americans use social media. Pew Research Center. Retrieved from http://www.pewinternet.org/files/oldmedia//Files/Reports/2011/Why\%20Americans\%20Use\%20Social\%20Media.pdf

Somers, D. (2017, February). Do colleges look at your social media accounts? U.S. News \& World Report. Retrieved from https://www.usnews.com/education/best-colleges/articles/2017-02-10/colleges-really-are-looking-at-yoursocial-media-accounts

Sprecher, S., Treger, S., \& Wondra, J. D. (2013). Effects of self-disclosure role on liking, closeness, and other impressions in get-acquainted interactions. Journal of Social and Personal Relationships, 30, 497-514. https://doi.org/10.1177/0265407512459033

Steijn, W. M. P., \& Schouten, A. P. (2013). Information sharing and relationships on social networking sites. Cyberpsychology, Behavior and Social Networking, 16, 582-587. https://doi.org/10.1089/cyber.2012.0392

Stvilia, B., Twidale, M. B., Smith, L. C., \& Gasser, L. (2005). Assessing information quality of a community-based encyclopedia. In Proceedings of the International Conference on Information Quality (pp. 442-454). https://doi.org/10.1.1.78.6243

Sunnafrank, M. J. (1986). Predicted outcome value during initial interactions: A reformulation of uncertainty reduction theory. Human Communication Research, 13, 3-33. https://doi.org/10.1111/j.1468-2958.1986.tb00092.x

Taddei, S., \& Contena, B. (2013). Privacy, trust and control: Which relationships with online self-disclosure? Computers in Human Behavior, 29, 821-826. https://doi.org/10.1016/j.chb.2012.11.022

Taylor, D. A. (1979). Motivational bases. In G. J. Chelune (Ed.), Self-disclosure: Origins, patterns, and implications of openness in interpersonal relationships (pp. 110-151). San Francisco, CA: Jossey-Bass.

Tidwell, L. C., \& Walther, J. B. (2002). Computer-mediated communication effects on disclosure, impressions, and interpersonal evaluations. Human Communication Research, 28, 317-348. https://doi.org/10.1111/j.1468- 
Tobii Technology AB: How to catch your valentine's eye: Online dating eye-tracking study reveals that men look, women read (2012). Business Wire. Retrieved from

https://www.businesswire.com/news/home/20120207006032/en/tobii-technology-ab-catch-valentine's-eye-onlin

Toma, C. L., \& Hancock, J. T. (2012). What lies beneath: The linguistic traces of deception in online dating profiles. Journal of Communication, 62, 78-97. https://doi.org/10.1111/j.1460-2466.2011.01619.x

Utz, S. (2010). Show me your friends and I will tell you what type of person you are: How one's profile, number of friends, and type of friends influence impression formation on social network sites. Journal of Computer-Mediated Communication, 15, 314-335. https://doi.org/10.1111/j.1083-6101.2010.01522.x

Utz, S. (2015). The function of self-disclosure on social network sites: not only intimate, but also entertaining selfdisclosure increases the feeling of connection. Computers in Human Behavior, 45, 1-10.

https://doi.org/10.1016/j.chb.2014.11.076

Walther, J. B. (1992). Interpersonal effects in computer-mediated interaction: A relational perspective.

Communication Research, 19, 52-90. https://doi.org/10.1177/009365092019001003

Walther, J. B. (1993). Impression development in computer-mediated interaction. Western Journal of Communication, 57, 381-398. https://doi.org/10.1080/105703193093744

Wheeless, L. R., \& Grotz, J. (1976). Conceptualization and measurement of reported self-disclosure. Human Communication Research, 2, 338-346. https://doi.org/10.1111/j.1468-2958.1976.tb00494.x

\author{
Correspondence to: \\ Lemi Baruh \\ Department of Media and Visual Arts \\ Koç University \\ Rumelifeneri Yolu \\ Istanbul 34450 \\ Turkey \\ E-mail: Ibaruh(at)ku.edu.tr
}

Editorial record: First submission received on October 16, 2017. Revisions received on February 4, 2018, and May 14, 2018. Accepted for publication on June 4, 2018.

\title{
About Authors
}

Lemi Baruh, (Ph.D. University of Pennsylvania, Annenberg School for Communication, 2007) is Associate Professor at the Department of Media and Visual Arts, College of Social Sciences and Humanities at Koç University in Turkey. Lemi Baruh's research interests include new media technologies, particularly focusing on social media usage patterns, identity, surveillance, privacy attitudes and privacy protective behavior, and culture of voyeurism.

Zeynep Cemalcılar (Ph.D. University of Texas, 2003) is Associate Professor at Department of Psychology, College of Social Sciences and Humanities at Koç University in Turkey. She is interested in studying social psychological theories and issues as processes applied to real world situations, particularly understanding the daily lives of "youth". Her most recent research focuses on understanding the dynamics of (1) use of technology in the social life. (2) prosocial behavior with a special attention on initiation and sustainability of volunteerism; (3) subjective socioeconomic status and its effect on individual well-being; (4) social psychological interventions in the educational context; and (5) culture. 